\title{
BDNF Overexpression in the Ventral Tegmental Area Prolongs Social Defeat Stress-induced Cross-Sensitization to Amphetamine and Increases $\Delta$ FosB Expression in Mesocorticolimbic Regions of Rats
}

\author{
Junshi Wang ${ }^{1,2}$, Sanya Fanous ${ }^{1,5}$, Ernest F Terwilliger ${ }^{3}$, Caroline E Bass ${ }^{3,6}$, Ronald P Hammer Jr ${ }^{1,2,4}$ and \\ Ella M Nikulina*, I \\ 'Department of Basic Medical Sciences, University of Arizona College of Medicine, Phoenix, AZ, USA; ${ }^{2}$ Neuroscience Program, Arizona State \\ University, Tempe, AZ, USA; ${ }^{3}$ Beth Israel Deaconess Medical Center, Boston, MA, USA; ${ }^{4}$ Departments of Pharmacology and Psychiatry, University \\ of Arizona College of Medicine, Phoenix, AZ, USA
}

Social defeat stress induces persistent cross-sensitization to psychostimulants, but the molecular mechanisms underlying the development of cross-sensitization remain unclear. One candidate is brain-derived neurotrophic factor (BDNF). The present research examined whether ventral tegmental area (VTA) BDNF overexpression would prolong the time course of cross-sensitization after a single social defeat stress, which normally produces transient cross-sensitization lasting $<$ I week. $\Delta$ FosB, a classic molecular marker of addiction, was also measured in mesocorticolimbic terminal regions. Separate groups of intact male Sprague-Dawley rats underwent a single episode of social defeat stress or control handling, followed by amphetamine (AMPH) challenge 3 or 14 days later. AMPH cross-sensitization was apparent 3, but not 14, days after stress. Intra-VTA infusion of adeno-associated viral (AAV-BDNF) vector resulted in a twofold increase of BDNF level in comparison to the group receiving the control virus (AAV-GFP), which lasted at least 45 days. Additionally, overexpression of BDNF in the VTA alone increased $\triangle F$ osB in the nucleus accumbens (NAc) and prefrontal cortex. Fourteen days after viral infusions, a separate group of rats underwent a single social defeat stress or control handling and were challenged with AMPH I4 and 24 days after stress. AAV-BDNF rats exposed to stress showed prolonged cross-sensitization and facilitated sensitization to the second drug challenge. Immunohistochemistry showed that the combination of virally enhanced VTA BDNF, stress, and AMPH resulted in increased $\Delta$ FosB in the NAc shell compared with the other groups. Thus, elevation of VTA BDNF prolongs cross-sensitization, facilitates sensitization, and increases $\triangle$ FosB in mesocorticolimbic terminal regions. As such, elevated VTA BDNF may be a risk factor for drug sensitivity.

Neuropsychopharmacology (2013) 38, 2286-2296; doi:I0.1038/npp.2013.130; published online 19 June 2013

Keywords: VTA; BDNF; social defeat; $\Delta$ FosB; cross-sensitization; amphetamine

\section{INTRODUCTION}

Cross-sensitization is defined as the augmented behavioral response to a drug challenge produced by intermittent exposure to an agent other than the challenge drug, such as stress or another drug (Antelman et al, 1980; Stewart and

*Correspondence: Dr EM Nikulina, Department of Basic Medical Sciences, University of Arizona College of Medicine, Phoenix, 425N 5th Street, Phoenix, AZ 85004, USA, Tel: + I 602827 2I 68, Fax: + I 602 827 2130, Email: nikulina@email.arizona.edu

${ }^{5}$ Current address: National Institute on Drug Abuse, Behavioral Neuroscience, 25I Bayview Boulevard, Suite 200, Baltimore, MD 21224, USA.

${ }^{6}$ Current address: Department of Pharmacology and Toxicology, School of Medicine and Biomedical Sciences, University at Buffalo, Buffalo, NY, USA.

Received 19 October 2012; revised I4 May 2013; accepted I4 May 2013; accepted article preview online 21 May 2013
Badiani, 1993). In humans, stressful life events increase vulnerability to drugs of abuse, particularly psychomotor stimulants (Sinha, 2008). Likewise, it has been demonstrated in animal models that various forms of stress can increase sensitivity and vulnerability to drugs of abuse (de Jong et al, 2005b; Miczek et al, 2004; Nikulina et al, 2004; Piazza et al, 1990; Robinson et al, 1985).

The mesocorticolimbic circuitry is comprised of the ventral tegmental area (VTA), where dopamine neurons are located, and its projection areas: the prefrontal cortex (PFC), nucleus accumbens (NAc), hippocampus, and amygdala (Swanson, 1982). Both stress and psychostimulants activate the mesocorticolimbic dopamine system and increase dopamine release in VTA terminal regions (Di Chiara and Imperato, 1988; Tidey and Miczek, 1996). Although aversive social events such as social stress can increase vulnerability to the development of drug sensitization, not all individuals exposed to social stress become 
sensitized to drugs of abuse. These differences may result from individual genetic differences.

One candidate gene for such individual differences is brain-derived neurotrophic factor (BDNF). Genetic addiction studies in humans have determined that a polymorphism in the bdnf gene is associated with vulnerability for polysubstance abuse (Uhl et al, 2001). In particular, the presence of the BDNF $66 \mathrm{Val}$ allele, which confers greater activity-dependent secretion of BDNF compared with the BDNF 66Met allele (Egan et al, 2003), is associated with greater vulnerability to drug addiction (Cheng et al, 2005; Flanagin et al, 2006; Tsai, 2007). This finding, coupled with the fact that BDNF has an important role in the survival of dopamine neurons (Baquet et al, 2005), activity-dependent neural plasticity (Cohen-Cory et al, 2010), and learning and memory (Bekinschtein et al, 2008), places BDNF in a good position to influence response to both stress or drugs of abuse.

Several lines of research support a role for VTA BDNF in stress- and drug-related behavior. In rodents, intermittent social defeat stress elevates BDNF expression in the VTA (Fanous et al, 2010) and produces lasting cross-sensitization to amphetamine (AMPH) (Nikulina et al, 2004). Furthermore, infusion of BDNF into the VTA increases locomotor response to cocaine (Pierce and Bari, 2001) and facilitates drug sensitization (Horger et al, 1999). By contrast, depletion of BDNF in the VTA prevents the social aversion induced by chronic social defeat stress and increases general social interaction (Berton et al, 2006; Fanous et al, 2011). As VTA BDNF is involved in modulating responses to both social defeat stress and psychostimulants, VTA BDNF may have a role in sensitivity to psychostimulants after social defeat stress. The present study examined the association between enhanced VTA BDNF and increased vulnerability to cross-sensitization and sensitization to AMPH in the presence of social defeat stress.

Another factor that may affect stress-induced sensitization to psychostimulants is $\Delta \mathrm{FosB}$, a truncated form of the FosB transcription factor. $\Delta$ FosB is considered a molecular marker for chronic stimulation of reward circuitry, stressinduced neuroplasticity, and sensitization to psychostimulants. $\triangle \mathrm{FosB}$, barely detectable immediately after acute stimuli, accumulates to considerable levels after repeated social defeat stress or repeated drug administration and persists due to its stability (Nestler et al, 1999; Nikulina et al, 2008; Perrotti et al, 2004). $\Delta$ FosB regulates the expression of many neuroplasticity-related genes in reward circuitry after chronic drug exposure (McClung et al, 2004), and increased $\triangle \mathrm{FosB}$ in reward circuitry enhances the sensitivity to psychostimulants, such as cocaine (Kelz et al, 1999). In the current study, we characterized $\Delta$ FosB in VTA terminal regions as a molecular marker for long-term sensitization related to neuroadaptive changes.

Here we overexpressed BDNF in the VTA using an adenoassociated virus (AAV) vector to examine effects on AMPH sensitization in two non-sensitizing behavioral manipulations: (1) long-term cross-sensitization after a single episode of social defeat stress and (2) sensitization after non-sensitizing repeated dosing regimen of AMPH injections (Segal and Mandell, 1974). We chose a single social defeat paradigm because single social defeat stress-induced effects are transient (de Jong et al, 2005b; Miczek et al,
1999) in comparison to intermittent social defeat stress that result in long-lasting cross-sensitization (Covington and Miczek, 2001; Nikulina et al, 2004). We also investigated whether a single social defeat stress exposure in the presence of elevated VTA BDNF could induce long-lasting $\Delta$ FosB expression in mesocorticolimbic projection regions.

\section{MATERIALS AND METHODS}

\section{Animals}

Subjects were male Sprague-Dawley rats (Charles River Laboratories, Hollister, CA). Rats weighed $225-250 \mathrm{~g}$ upon arrival and were acclimated to laboratory conditions for 1 week before the start of experiments. All subjects were maintained under a reverse light/dark cycle $(12 \mathrm{~h}: 12 \mathrm{~h}$, lights off at 0900 hours), with unlimited access to food (Purina Rodent Diet, Brentwood, MO) and water. After the acclimation period, rats underwent stereotaxic surgery and were single-housed for the remainder of study in standard plastic cages $\left(25 \times 50 \times 20 \mathrm{~cm}^{3}\right)$. Male Long-Evans rats (Charles River Laboratories), termed 'residents', were pair-housed with females in larger $\left(37 \times 50 \times 20 \mathrm{~cm}^{3}\right)$ cages. Residents were screened for aggressive behavior as described previously (Nikulina et al, 2004). All experimental procedures were approved by the Arizona State University Institutional Animal Care and Use Committee and conducted in accordance with the Guide for the Care and Use of Laboratory Animals (National Research Council, 1996). All efforts were used to minimize suffering and to limit the number of animals used.

\section{Viral Vector}

Pseudotyped AAV2/10 vectors were used in all the experiments. The AAV2/10 rep/cap plasmid provided the AAV2 replicase and AAV10 capsid genes (Gao et al, 2002), while adenoviral helper functions were supplied by the pHelper plasmid (Stratagene, La Jolla, CA). The AAV plasmids contain a transgene cassette, which consists of the cytomegalovirus promoter, and either the gene for rat BDNF fused to enhanced green fluorescent protein or GFP alone (GFP gift from R. Klein), followed by a combined intron/polyadenylation signal derived from SV40. These elements are flanked by two AAV2 inverted terminal repeats. A standard triple transfection protocol was used to generate the helper-free pseudotyped AAV2/10 vectors as previously described (Xiao et al, 1998). Briefly, the three plasmids were co-transfected into HEK-293 cells (Stratagene, La Jolla, CA) via calcium phosphate precipitation. Cells were harvested $48 \mathrm{~h}$ later, resuspended in DMEM, freeze-thawed with dry ice-ethanol slurry three times and centrifuged to produce a clarified cell lysate. The resulting viral stocks produced either GFP (AAV-GFP, as control virus) or BDNF-GFP (AAV-BDNF) upon infection and were stored at $-80^{\circ} \mathrm{C}$ before use.

\section{Intracranial Viral Infusion}

Rats were anesthetized with isofluorane and positioned in a stereotaxic frame (Leica Angle Two; Richmond, IL). Two holes were drilled at stereotaxic coordinates (AP $-5.1 \mathrm{~mm}$; 
ML $\pm 2.15 \mathrm{~mm}$ from the bregma) on the surface of skull, and Hamilton syringes (Model $7105 \mathrm{KH}$; Reno, NV) with 24 gauge injector tips were lowered through the holes bilaterally at a $10^{\circ}$ angle until needle tips reached the VTA (AP $-5.1 \mathrm{~mm} ; \mathrm{ML} \pm 0.6 \mathrm{~mm}$; DV $-8.8 \mathrm{~mm}$ from the bregma; Paxinos and Watson, 2007); $0.5 \mu \mathrm{l}$ of virus was bilaterally infused into each side of the VTA for $10 \mathrm{~min}$ at a speed of $0.05 \mu \mathrm{l} / \mathrm{min}$. After infusion, the syringes remained in the infusion sites for $5 \mathrm{~min}$ to prevent retrace of virus.

\section{Confirmation of Viral Efficacy}

To confirm viral efficacy in enhancing VTA BDNF at the relevant time points for the behavioral experiments, we examined VTA BDNF expression by BDNF immunohistochemistry 14 and 45 days after viral infusions. Rats received AAV-GFP or AAV-BDNF. One cohort of rats was used only to measure VTA BDNF expression 14 days after viral infusions. Measurement of VTA BDNF expression 45 days after viral infusions was performed in tissue from the rats used in Experiment 2 below.

All placements of infusion sites were confirmed based on observation of GFP expression in serially collected brain sections. The cases in which infusion sites were inaccurate were excluded from further assessment.

\section{Experimental Design}

A timeline of the experiments is presented in Figure 1. Based on the finding that VTA BDNF is elevated from 2 weeks to at least 45 days after viral infusions (described in RESULTS below), we waited at least 2 weeks after the viral infusion to commence any experimental procedures.

Experiment 1: Time course of a single social defeat stress-induced cross-sensitization. Rats were randomly assigned to four groups, exposed to either a single social

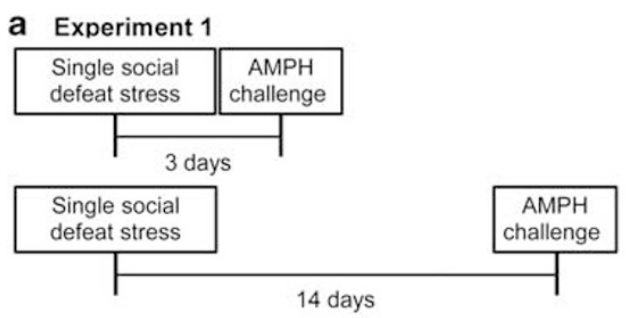

b Experiment 2

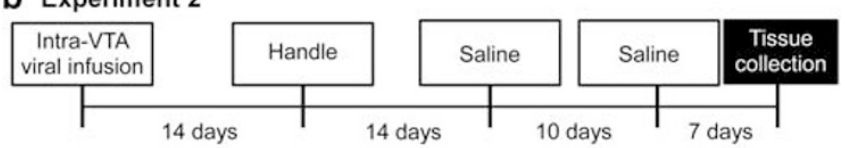

C Experiment 3

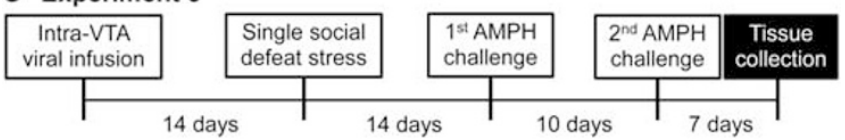

Figure I Schematic of experimental design. (a) Experiment I: Time course of single social defeat stress-induced cross-sensitization to AMPH. (b) Experiment 2: Effect of VTA BDNF overexpression on molecular alterations in mesocorticolimbic areas. (c) Experiment 3: Effect of single social defeat stress and VTA BDNF overexpression on behavioral sensitization to $\mathrm{AMPH}$ and molecular alterations. defeat stress or handling procedure, then received d-amphetamine sulfate $(1.0 \mathrm{mg} / \mathrm{kg}$, i.p.; Sigma-Aldrich; St Louis, MO) either 3 days $(n=6$ each) or 14 days $(n=4$ and 5 , respectively) after defeat or the handling procedure (Figure 1a). Following AMPH challenge, locomotor activity was tracked and assessed.

Experiment 2: Molecular alterations induced by VTA $B D N F$ overexpression. Rats received bilateral intra-VTA infusion of either AAV-GFP $(n=4)$ or AAV-BDNF $(n=7)$. Two weeks after the surgery, rats were handled, followed 2 weeks later by $0.9 \%$ saline $(1.0 \mathrm{ml} / \mathrm{kg}$, i.p.) injection. Brain tissue was collected and processed 45 days after viral infusion surgery (Figure $1 \mathrm{~b}$ ). BDNF in the VTA and $\triangle$ FosB expression in the PFC and NAc were examined.

Experiment 3: Effect of single social defeat stress and VTA $B D N F$ overexpression on behavioral sensitization to $A M P H$ and molecular alterations. Rats were randomly assigned to four groups based on two experimental factors: virus (AAV-GFP vs AAV-BDNF) and behavioral treatment (handling $v s$ single social defeat). The groups were: AAVGFP-handled $(n=7)$, AAV-GFP-stressed $(n=7)$, AAVBDNF-handled $(n=8)$, and AAV-BDNF-stressed $(n=7)$. The stressed groups underwent a single social defeat stress exposure 2 weeks after the surgery, at which time the handled groups were handled, followed by two AMPH $(1.0 \mathrm{mg} / \mathrm{kg}$, i.p.) challenge injections 14 and 24 days after stress. To examine whether prolonged cross-sensitization was induced by VTA BDNF overexpression in rats exposed to single social defeat stress, the first AMPH challenge was given 2 weeks after defeat or handling. Three rats were excluded from this study due to artifact during locomotor tracking. The second AMPH challenge was given 10 days later (24 days after defeat stress; one rat was excluded due to an artifact during tracking). All animals were euthanized at day 45 after surgery, whereupon brain tissue was collected and processed (Figure 1c). Besides locomotor activity, $\mathrm{BDNF}$ single labeling and BDNF/TH double labeling in the $\mathrm{VTA}$ and $\triangle \mathrm{FosB}$ expression in the PFC and NAc were examined. The sample numbers of different immunohistochemical procedures varied due to the exclusion of samples with occasional heterogeneity of section quality.

\section{Social Defeat Stress}

Social defeat stress consisted of a short aggressive confrontation between an aggressive resident rat and an experimental intruder rat as described in detail previously (Nikulina et al, 2004). After removing the female from the resident's cage, an experimental intruder rat was placed into the home cage of a resident male rat under a stainless steel protective cage $\left(15 \times 25 \times 15 \mathrm{~cm}^{3}\right)$ for $5 \mathrm{~min}$, then the protective cage was removed, and the resident displayed aggressive behavior; 'defeat' occurred when the intruder exhibited a supine posture for at least $4 \mathrm{~s}$. Aggressive interactions were $2-5 \mathrm{~min}$ in duration. The protective cage was then replaced for an additional 15-min exposure, after which the intruder was returned to its home cage. Control rats were handled and weighed on the days their counterparts were stressed and weighed. 


\section{Locomotor Tracking}

For 2 consecutive days immediately before AMPH challenge, rats were given a $0.9 \%$ saline injection $(1.0 \mathrm{ml} /$ $\mathrm{kg}$, i.p.) in their home cages. Rats inside their home cages were placed into the locomotion tracking arena for $1 \mathrm{~h}$ to acclimate to the testing environment and injection procedure. On the drug challenge day, rats were placed into the locomotion tracking arena within their home cages, habituated to the testing environment for $30 \mathrm{~min}$ during which locomotion was tracked, injected with saline followed by tracking for $40 \mathrm{~min}$, and then challenged with $\mathrm{AMPH}$ followed by tracking for $70 \mathrm{~min}$. Peak locomotor activity in response to AMPH was achieved 10-50 min after challenge. Locomotor activity was assessed using Videotrack (Viewpoint Life Sciences; Montreal, Canada); total distance travelled in the form of large ambulatory movements $(>10 \mathrm{~cm})$ was measured in 10-min bins. The dosage of AMPH used herein mainly induces large ambulatory movements (Geyer et al, 1987), so total distance of such movements can be used as an indicator of the extent of psychomotor sensitization in response to $\mathrm{AMPH}$.

\section{Perfusion and Tissue Processing}

Forty-five days after surgery, all rats were deeply anesthetized with sodium pentobarbital $(100 \mathrm{mg} / \mathrm{kg}$, i.p.) and perfused transcardially with $10 \mathrm{ml}$ of $10 \%$ heparin in $0.1 \mathrm{M}$ phosphate-buffered saline (PBS; pH 7.4) followed by $250 \mathrm{ml}$ of $4 \%$ paraformaldehyde in $0.1 \mathrm{M}$ phosphate buffer $(\mathrm{pH}$ 7.4). Brains were post-fixed for $1.5 \mathrm{~h}$ in the same fixative at $4{ }^{\circ} \mathrm{C}$, soaked in $12.5 \%$ sucrose, then in $25 \%$ sucrose in $0.1 \mathrm{M}$ PBS at $4{ }^{\circ} \mathrm{C}$ until saturated, then stored at $4{ }^{\circ} \mathrm{C}$ before sectioning. Brains were sectioned at $20 \mu \mathrm{m}$ in a cryostat at $-22{ }^{\circ} \mathrm{C}$ and thaw-mounted onto glass slides (Superfrost Plus; Fisher; Waltham, MA). Sections were collected from +3.2 to $+2.8 \mathrm{~mm}$ from bregma for the PFC, +1.8 to $+0.8 \mathrm{~mm}$ from bregma for the NAc, and -4.8 to $-5.6 \mathrm{~mm}$ from bregma for the VTA (Paxinos and Watson, 2007).

\section{Immunohistochemistry}

Sections were washed in $0.05 \mathrm{M}$ potassium phosphatebuffered saline (KPBS), then blocked for $1 \mathrm{~h}$ in $10 \%$ normal donkey serum and $0.4 \%$ Triton $\mathrm{X}-100$ in $0.05 \mathrm{M}$ KPBS. Sections were then incubated with primary antibody: BDNF (AB1779SP, 1:3000 dilution; Millipore; Temecula, CA) or FosB (SC-48, 1: 10000 dilution; Santa Cruz Biotechnology; Santa Cruz, CA). The FosB antibody used here targets the N terminal of FosB protein contained in both FosB and $\Delta$ FosB. However, based on the timeline of the present research, FosB-like labeling would primarily capture accumulation of $\triangle F o s B$, because FosB expression is transient and only $\Delta$ FosB persists after stimulation (Perrotti et al, 2004). Following incubation with primary antibody for $48 \mathrm{~h}$ at $4{ }^{\circ} \mathrm{C}$, slides were washed in $0.05 \mathrm{M}$ KPBS and incubated for $1 \mathrm{~h}$ in biotin-conjugated goat anti-rabbit serum $(1: 200$ dilution in blocking solution, Vectastain ABC kit; Vector Laboratories; Burlingame, CA). After washing in $0.05 \mathrm{M} \mathrm{KPBS}$, sections were incubated with avidin-biotin-peroxidase complex (ABC kit, Vector Laboratories) for $1 \mathrm{~h}$, then washed again, and developed using $\mathrm{DAB}$ chromogen with nickel (DAB
Peroxidase Substrate kit, Vector Laboratories). After dehydration in graded concentrations of ethanol and xylene, coverslips were applied.

To examine the cellular localization of BDNF expression in the VTA of animals that showed persistent crosssensitization, we performed fluorescent double labeling of BDNF and tyrosine hydroxylase (TH). Primary antibodies, rabbit anti-BDNF (AB1779SP, 1:500 dilution; Millipore; Temecula, CA) and mouse anti-TH (SC-7837, 1:500 dilution, Santa Cruz Biotechnology; Santa Cruz, CA), were applied simultaneously and incubated for $48 \mathrm{~h}$ at $4{ }^{\circ} \mathrm{C}$. After incubation with biotinylated goat anti-rabbit IgG (1:200 dilution, Vector Laboratories) for $1 \mathrm{~h}$, Alexa Fluor 488 AntiRabbit conjugated streptavidin and Alexa Fluor 548 Goat Anti-Mouse (1:500 dilution, Invitrogen, San Diego, CA) were applied for $2 \mathrm{~h}$. After washing with $0.05 \mathrm{M} \mathrm{KPBS}$, coverslips were applied with ProLong Gold Antifade Reagent with DAPI (Invitrogen, San Diego, CA).

\section{Image Analysis}

Tissue sections were examined for the presence of chromogen or fluorophore reaction products using a Zeiss Axioskop microscope with $\times 20$ or $\times 40$ objectives; selected areas were captured and digitized using a color digital video camera (MBF Biosciences; Williston, VT) or AxioCam MR (Zeiss) interfaced to the microscope. A cell profile was considered labeled if its pixel intensity was $>2$ SDs greater than the background, as calculated by Stereo Investigator software (MBF Biosciences). Fluorescent-labeled cells were counted manually, first in single channels for single labeling, and then in merged channels for double labeling. At least three adjacent sections were analyzed for each brain region per animal, and labeling density was calculated by dividing the estimated total number of labeled profiles by the total area analyzed.

\section{Statistics}

In experiment 1, one-way ANOVA (between-subjects factor: handling $v s$ stress) was used to analyze locomotor activity during the peak locomotor response period (10-50 min after AMPH injection). In experiment 2, one-way ANOVA was used to analyze the number of BDNF or $\triangle$ FosB-labeled cells in saline-treated animals (between-subjects factor: AAV$\mathrm{BDNF}$ vs AAV-GFP). In experiment 3, locomotor activity and immunohistochemical data were analyzed by two-way ANOVA (between-subjects factors: viral vector (AAV-BDNF vs AAV-GFP) and behavioral treatment (handling vs stress)). Three-way mixed ANOVA with repeated measures (two between-subjects factors: viral vector (AAV-BDNF vs AAV-GFP) and behavioral treatment (handling vs stress); one within-subjects factor: number of AMPH injections (first $v s$ second)) was used to analyze locomotor activity in response to the first and the second $\mathrm{AMPH}$ challenge. In a few cases, an optical artifact produced an unrecoverable error in locomotor tracking. Therefore, several cases were excluded due to the presence of this artifact. To assure that the same cases were assessed repeatedly across both challenge sessions by three-way ANOVA with repeated measures, samples with such artifact in either of the two AMPH challenges were excluded. Thus, the final number of 
cases assessed using three-way mixed ANOVA with repeated measures is $n=6$ per group.

T-test was used for planned comparisons between AAVBDNF-stressed and all the other groups when significant interaction was not present, and post-hoc Tukey's test was used in the presence of significant interaction. All data are reported as mean \pm SEM. Results were considered significant if $p \leqslant 0.05$.

\section{RESULTS}

\section{Experiment 1}

Time Course of Single Social Stress-Induced CrossSensitization. To measure the time course of single social defeat stress-induced cross-sensitization in naive rats, locomotor response to AMPH challenge was evaluated in adult male Sprague-Dawley rats 3 or 14 days after exposure to a single social defeat or control handling. Rats exposed to single social defeat 3 days earlier exhibited significantly more total locomotor activity after AMPH than rats handled 3 days earlier (measured 10-50 min after AMPH challenge; $\mathrm{F}_{(1,11)}=7.170, p=0.023$; Figure $\left.2 \mathrm{a}\right)$, reflecting the presence of cross-sensitization. No difference in total locomotor activity was observed between stressed and handled rats in a separate cohort that were challenged with AMPH 14 days after exposure to single social defeat stress or handling $\left(F_{(1,7)}=0.230, p=0.646\right.$; Figure $\left.2 b\right)$. This indicates that cross-sensitization after a single defeat is short-lasting and detectable 3 days, but not 14 days, later.

\section{Experiment 2}

Confirmation of viral efficacy. The viral infusion site was visualized using GFP as an indicator of transfection (Figure 3a). Based on GFP expression from serially collected sections, we observed that transfected neurons in the VTA extend approximately $300 \mu \mathrm{m}$ in diameter on the rostralcaudal axis, and $200 \mu \mathrm{m}$ in diameter on dorsal-ventral and medial-lateral axes around the infusion site. Expression of viral product at 45 days after infusion is consistent with the observation that AAV-mediated transgene expression persists 1-3 months in neurons after transfection (Klein et al, 1998). To compare the increase in VTA BDNF after AAVBDNF across time points, VTA BDNF expression was normalized to that of the AAV-GFP control group at each respective time point (Figure $3 \mathrm{c}$ ). Fourteen and 45 days after viral infusion, we observed twofold increase of BDNF in rats receiving AAV-BDNF compared with those receiving AAVGFP: 14 days $\mathrm{F}_{(1,7)}=11.105, p=0.013$; Figure $3 \mathrm{c} ; 45$ days $\mathrm{F}_{(1,9)}=7.312, p=0.027$; Figure $\left.3 \mathrm{~b}-\mathrm{d}\right)$. At both 14 and 45 days, the volume of infection was approximately $25 \%$ of the rostral VTA (bregma -4.8 to -5.6 ) around the infusion site (bregma - 5.1).

$\triangle F o s B$ expression after BDNF overexpression in the VTA of drug-naive rats. VTA BDNF overexpression alone increased $\triangle$ FosB labeling in anterior cingulate (ACG; $\left.\mathrm{F}_{(1,6)}=9.880, p=0.020\right)$, prelimbic $\left(\mathrm{PRL} ; \mathrm{F}_{(1,6)}=12.930\right.$, $p=0.007)$, and infralimbic (IL; $\left.\mathrm{F}_{(1,6)}=15.620, p=0.008\right)$ regions of the PFC (Figures $4 \mathrm{a}$ and $\mathrm{c}$ ) and in the NAc core $\left(\mathrm{F}_{(1,8)}=16.108, \quad p=0.043\right)$ and shell $\left(\mathrm{F}_{(1,8)}=11.978\right.$,
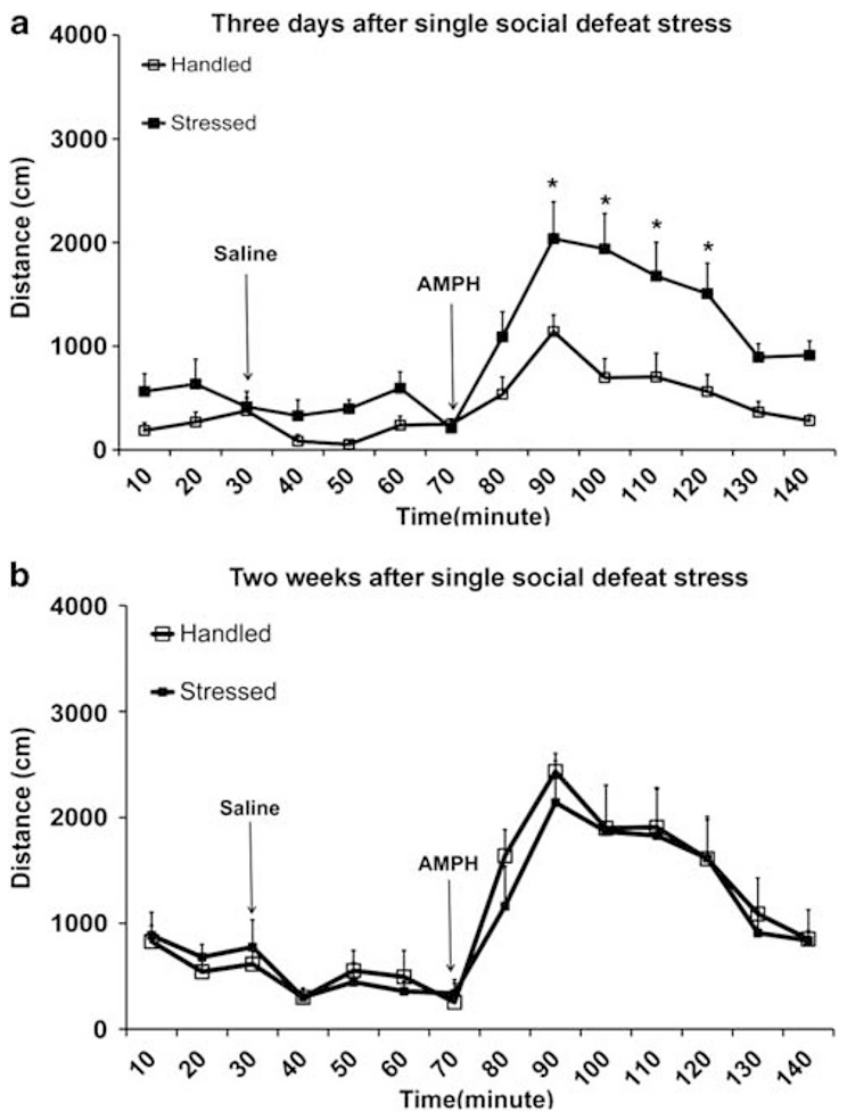

Figure 2 Cross-sensitization to AMPH after a single episode of social defeat stress is observed 3 days, but not 14 days, after stress. Rats were exposed to a single episode of social defeat stress or handling and then challenged with AMPH (1.0 mg/kg, i.p) 3 days or 14 days later. Distance traveled was measured before and after saline injection and following AMPH (I.0 mg/ $/ \mathrm{kg}$, i.p.) challenge. Injection times are indicated by vertical arrows. (a) Locomotor activity in response to AMPH challenge 3 days after single social defeat stress $(* p \leqslant 0.05)$. (b) Locomotor activity in response to AMPH challenge 14 days after single social defeat stress.

$p=0.011$; Figure $4 \mathrm{~b}$ and c) compared with the AAV-GFPsaline rats.

\section{Experiment 3}

Social defeat stress-induced cross-sensitization and sensitization to $A M P H$. To determine whether elevated VTA BDNF prolonged single social defeat stress-induced crosssensitization, rats receiving AAV-GFP control virus or AAV-BDNF were exposed to a single episode of stress or handling followed by AMPH $(1.0 \mathrm{mg} / \mathrm{kg}) 14$ days later. The absence of stress-induced cross-sensitization to AMPH 14 days later (Experiment 1) was confirmed in rats which received AAV-GFP (one-way ANOVA, $\mathrm{F}_{(1,12)}=1.873$, $p=0.198$ ). By contrast, AAV-BDNF-stressed rats showed significantly greater locomotor activity in response to the first AMPH injection compared with AAV-BDNF-handled rats (one-way ANOVA, $\mathrm{F}_{(1,12)}=4.730, p=0.050$ ). Two-way ANOVA showed significant main effects of stress $\left(\mathrm{F}_{(1,23)}=6.228, p=0.020\right)$ and AAV-BDNF $\left(\mathrm{F}_{(1,23)}=4.464\right.$, $p=0.046)$, but the interaction between the two factors was not significant $\left(\mathrm{F}_{(1,23)}=0.277, p=0.603\right.$; Figure $\left.5 \mathrm{a}\right)$. Ten days after the first AMPH challenge, a second $\mathrm{AMPH}$ 
a

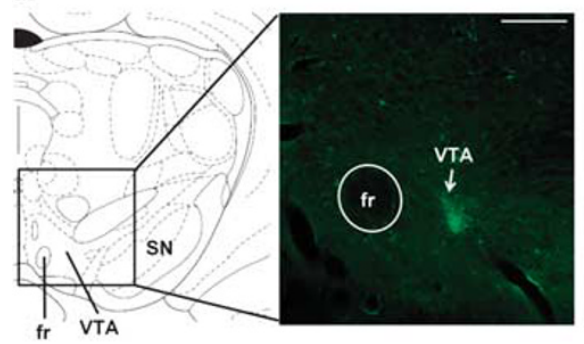

C BDNF at infusion site

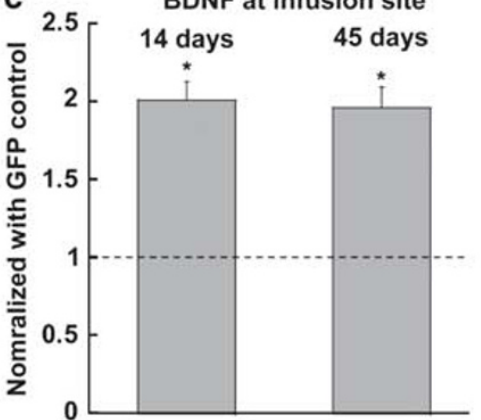

b
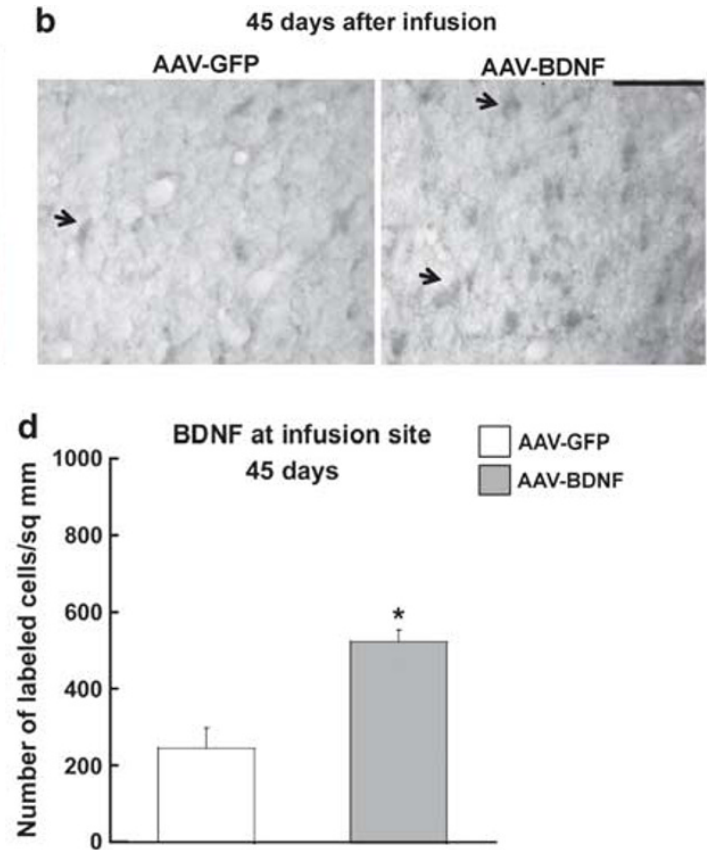

Figure 3 AAV-BDNF infusion into the VTA produces persistent overexpression of BDNF. (a) Brain atlas and representative image of AAV-GFP infusion site (arrow) in the VTA visualized by GFP fluorescence, bar $=200 \mu \mathrm{m}$; fr: fasciculus retroflexus, SN: substantia nigra. (b) Representative photomicrographs of BDNF labeling 45 days after AAV-BDNF infusion. Bar $=100 \mu \mathrm{m}$. BDNF expression near the infusion site is significantly increased after AAV-BDNF; solid arrow-BDNF-labeled neurons. (c) Number of BDNF-labeled cells at infusion site, normalized to AAV-GFP control, 14 and 45 days after infusion. (d) Number of BDNF-labeled cells at infusion site 45 days after infusion, in AAV-GFP and AAV-BDNF rats. * $p \leqslant 0.05$ compared with control AAV-GFP-saline rats.

challenge was given, and a significant main effect of AAV$\operatorname{BDNF}\left(\mathrm{F}_{(1,25)}=8.284, p=0.008\right)$ and interaction between stress and AAV-BDNF on locomotor activity was observed $\left(\mathrm{F}_{(1,25)}=5.950, p=0.022\right)$, but we observed no main effect of stress $\left(\mathrm{F}_{(1,25)}=1.587, p=0.219\right.$; Figure $\left.5 \mathrm{~b}\right)$. Additionally, AAV-BDNF-stressed rats showed significantly greater locomotor activity than the AAV-GFP-handled, AAV-GFPstressed and AAV-BDNF-handled groups in response to the second AMPH injection (post-hoc multiple comparisons: $p=0.008,0.001$, and 0.014, respectively; Figure 5c).

To examine locomotor response to a non-sensitizing AMPH dose regimen in rats with a history of stress exposure and enhanced VTA BDNF, we compared locomotor activity in response to first and second $\mathrm{AMPH}$ challenges within each group (Figure 5c). Analysis of the amplitude of variation of locomotor activity between the first and the second AMPH challenge was achieved using three-way ANOVA with repeated measures. The data showed significant interaction of AAV-BDNF and the number of $\mathrm{AMPH}$ injections $\left(\mathrm{F}_{(1,22)}=4.503, p=0.045\right)$. Also, a significant interaction among stress, AAV-BDNF, and the number of AMPH injections $\left(\mathrm{F}_{(1,22)}=5.463\right.$, $p=0.029)$ was observed. Furthermore, AAV-BDNF-stressed rats showed significantly augmented locomotor response to the second AMPH injection compared with the first AMPH injection (post-hoc multiple comparisons: $p=0.031$ ), indicating facilitated sensitization after repeated dosing. Although a weak increasing trend was present in AAVGFP-handled rats in response to multiple AMPH injections, this effect was not statistically significant $(p=0.09)$. No significant changes in locomotion after AMPH was observed in AAV-GFP-stressed or AAV-BDNF-handled rats (post-hoc multiple comparisons: $p=0.418$ and 0.241 , respectively, Figure 5c).

BDNF expression in VTA dopaminergic neurons. To characterize the distribution and phenotype of BDNFexpressing neurons in the VTA, double-label fluorescent immunohistochemistry was performed on tissue from Experiment 3. Two-way ANOVA of the total number of BDNF-expressing neurons in the rostral VTA also indicated a significant main effect of AAV-BDNF $\left(\mathrm{F}_{(1,22)}=41.381\right.$, $p=0.001)$ and an interaction between AAV-BDNF and stress approaching significance $\left(\mathrm{F}_{(1,22)}=4.055, p=0.056\right)$. Also, AAV-BDNF-stressed rats showed higher BDNF labeling across the entire rostral VTA compared with all the other groups (Figure 6a; post-hoc comparisons: $p \leqslant 0.05$ for all comparisons).

Furthermore, two-way ANOVA showed significant main effect of AAV-BDNF on BDNF/TH double-labeled cells in the rostral VTA $\left(\mathrm{F}_{(1,22)}=14.298, p=0.001\right)$; and significantly more BDNF/TH double-labeled cells were present in the rostral VTA in AAV-BDNF-stressed rats than in AAVGFP-handled or stressed rats ( $t$-test: $p=0.018$ and 0.001 , respectively; Figure $6 \mathrm{~b}$ and $\mathrm{c}$ ).

$\triangle F o s B$ in the mesocorticolimbic projection areas. Consistent with the effect of VTA BDNF overexpression on $\triangle \mathrm{FosB}$ expression in PRL and ACG cortices in drugnaive rats (Experiment 2), two-way ANOVA showed a significant main effect of $A A V-B D N F$ on $\triangle$ FosB expression 

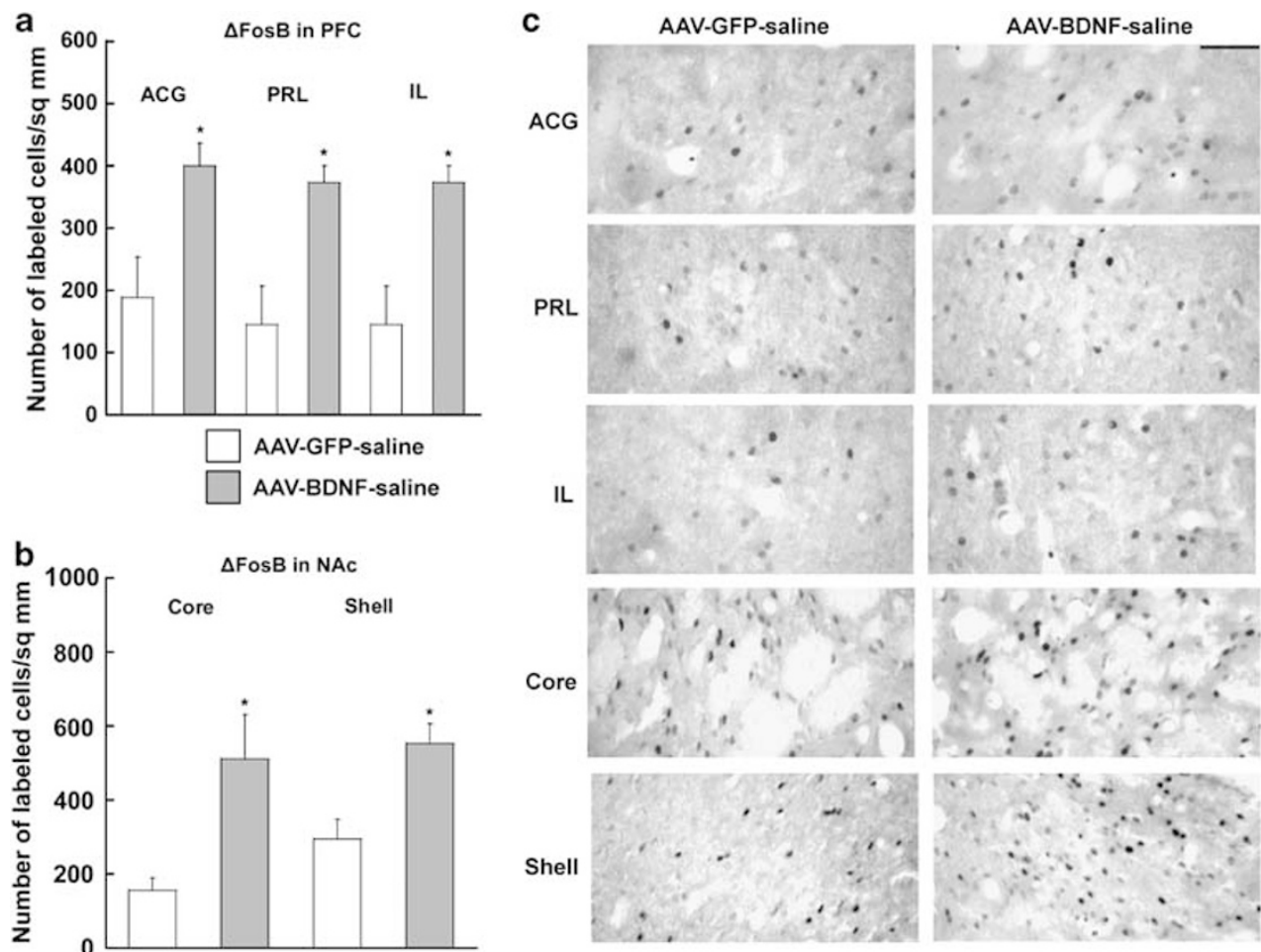

Figure 4 Persistent elevation of VTA BDNF leads to $\triangle$ FosB accumulation in the PFC and NAc. (a) $\triangle F o s B$ expression in the anterior cingulate (ACG), prelimbic (PRL), and infralimbic (IL) regions of the PFC. (b) AAV-BDNF infusion significantly increased $\triangle$ FosB expression in the NAc core and shell. * $p \leqslant 0.05$ compared with AAV-GFP-saline rats. (c) Representative photomicrographs of $\triangle$ FosB labeling in the PFC (ACG, PRL, IL areas) and NAc (core and shell) of AAV-GFP-saline and AAV-BDNF-saline rats; bar $=50 \mu \mathrm{m}$.

in both the ACG and PRL cortices in AMPH-treated rats (ACG: $\quad \mathrm{F}_{(1,21)}=6.837, \quad p=0.016 ; \quad$ PRL: $\quad \mathrm{F}_{(1,21)}=4.469$, $p=0.047$; Table 1$)$. In IL cortex, a main effect of stress was observed $\left(\mathrm{F}_{(1,21)}=4.941, p=0.037\right)$.

Among all the brain regions examined, the greatest induction of $\triangle$ FosB labeling was present in the NAc shell of AAV-BDNF-stressed animals (post-hoc multiple comparisons: $p \leqslant 0.01$ for all comparisons, Figures $7 \mathrm{a}$ and $\mathrm{b}$ ), where we observed significant main effect of stress $\left(\mathrm{F}_{(1,23)}=\right.$ $26.100, \quad p=0.001) \quad$ and AAV-BDNF $\quad\left(\mathrm{F}_{(1,23)}=39.670\right.$, $p=0.001)$ estimated by two-way ANOVA. Also, significant interaction between these two factors $\left(\mathrm{F}_{(1,23)}=10.010\right.$, $p=0.004)$ on $\Delta$ FosB expression was found in NAc shell. By contrast, no difference in $\triangle$ FosB cell counts was observed in the NAc core after AMPH challenge in any group ( $t$-test: $p>0.05$ for all comparisons; two-way ANOVA: behavioral treatment $\mathrm{F}_{(1,22)}=0.110, p=0.743$; virus: $\mathrm{F}_{(1,22)}=0.187, p=0.743$; behavioral treatment $\times$ virus: $\mathrm{F}_{(1,22)}=1.244, p=0.277$; Table 1$)$.

\section{DISCUSSION}

The present results demonstrate that virus-mediated enhancement of VTA BDNF expression both extends the time course of single social defeat stress-induced crosssensitization to AMPH and facilitates sensitization to a nonsensitizing dosing regimen of AMPH in rats exposed to a single episode of social defeat stress. We also show that enhancement of VTA BDNF alone is sufficient to increase $\Delta$ FosB expression in projection areas of the VTA.
Our behavioral results are consistent with previous findings (de Jong et al, 2005b) that single social defeatinduced cross-sensitization to AMPH is transient, apparent at 3 days but not at 14 days after a single exposure to social defeat. It is important to note that handled rats single-housed for 14 days showed higher locomotor response to AMPH than did handled rats singlehoused for 3 days. The increased locomotor response to AMPH in drug-naive rats handled/stressed 14 days earlier is likely due to the longer period of single-housing, a form of social isolation which can elevate rewarding effects of psychostimulants (Deroche et al, 1994) and can amplify the physiological effect of social defeat (de Jong et al, 2005a). In the present study, handled/stressed rats received control virus, and non-viral-treated rats that were single-housed for 2 weeks showed similar locomotor responses to AMPH. This suggests that single-housing induces an upward shift of locomotor activity to AMPH, which is consistent across experiments. Above all, single social defeat stress-induced cross-sensitization to AMPH was not observed 14 days after stress in non-viral treated rats or in rats that received the control GFP virus. The fact that cross-sensitization to AMPH was observed 14 days after single social defeat stress in the presence of enhanced VTA BDNF suggests that BDNF prolonged single stress-induced cross-sensitization. However, such an effect should be interpreted with caution, because persistent VTA BDNF elevation also might alter single social stress-induced crosssensitization at early time points. This possibility remains to be investigated. 

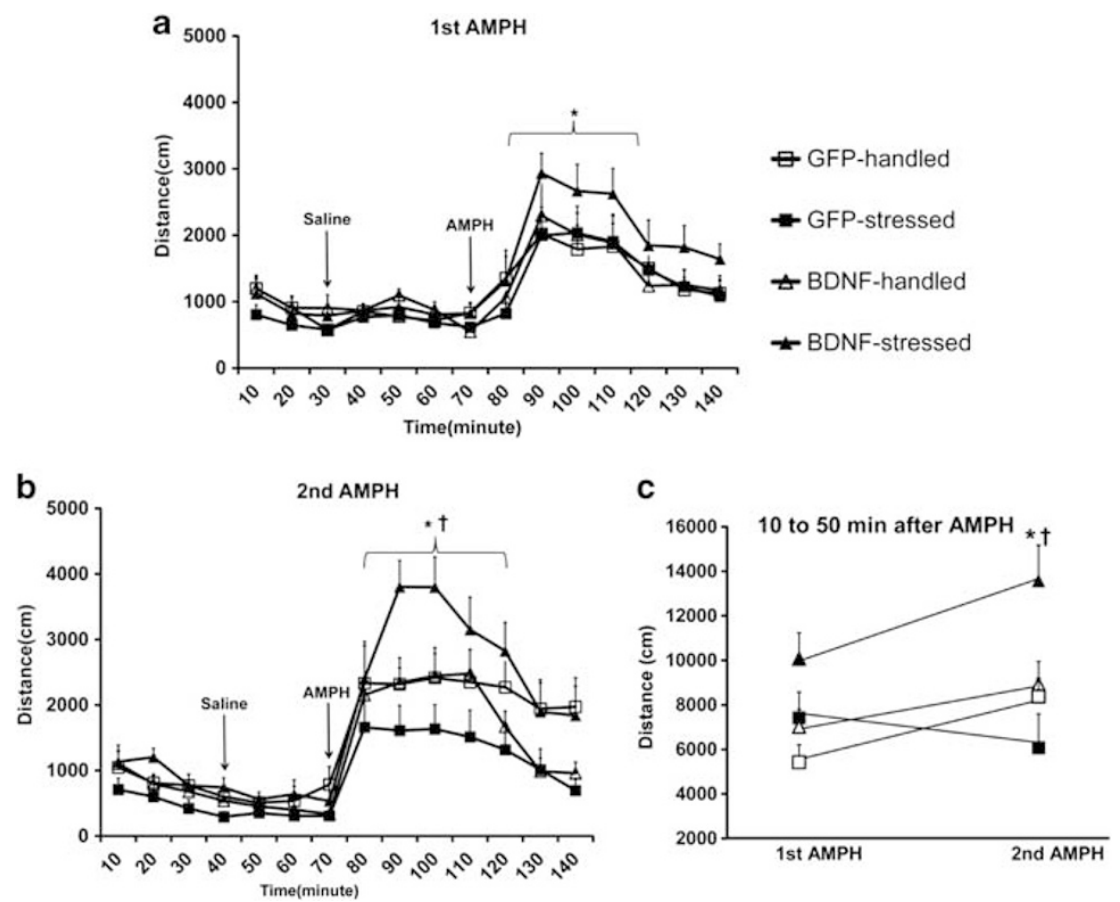

Figure 5 AAV-mediated VTA BDNF overexpression extends the time course of AMPH cross-sensitization after a single social defeat stress and facilitates drug sensitization after repeated AMPH. Locomotor activity (distance in $\mathrm{cm}$ ) over time (left) before and after saline, and following AMPH (I.0 mg/kg, i.p.) challenge ( $p \leqslant 0.05$ compared with all the other groups, ${ }^{\dagger} p \leqslant 0.05$ compared with the first AMPH injection). Injection times are indicated by vertical arrows; response to AMPH (total distance traveled in $\mathrm{cm}$ ) during the peak activity period 10-50 min after drug challenge. (a) Locomotor activity in response to the first AMPH challenge ( 14 days after stress or handling). (b) Locomotor activity in response to the second AMPH challenge (24 days after stress or handling). (c) Interaction plot of locomotor activity during the peak activity period in response to the first and the second AMPH challenge.
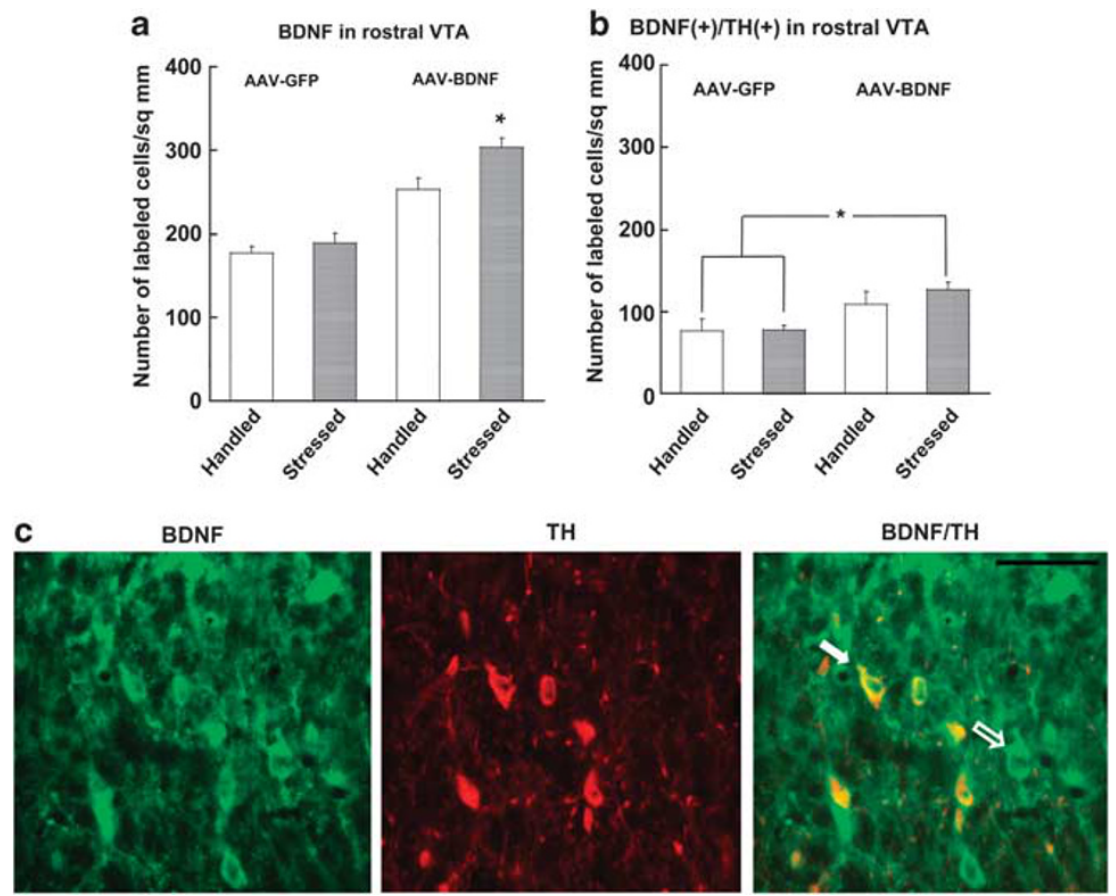

Figure 6 The number of BDNF expressed neurons increases in whole rostral VTA after combined VTA BDNF overexpression, single social stress, and repeated AMPH. (a) BDNF expression in whole rostral VTA, 45 days after viral infusion, with stress/handling procedure and two times AMPH challenges $(* p \leqslant 0.05$ compared with all the other groups), labeled with fluorophore-conjugated secondary antibodies. (b) BDNF/TH double labeling in VTA 45 days after viral infusion, with stress/handling procedure and two times AMPH challenges. (c) Representative microphotographs of fluorescent BDNF labeling (left), TH labeling (center), and BDNF/TH double-labeling (right); bar $=50 \mu \mathrm{m}$; filled arrow: BDNF and TH double-labeled cell; open arrow: non-dopaminergic BDNF-labeled cell. 
Table I Numbers of $\Delta$ FosB-Positive Cells per $\mathrm{mm}^{2}$ Present after Two AMPH Injections

\begin{tabular}{lcccc}
\hline Brain region & AAV-GFP-handled & AAV-GFP-stressed & AAV-BDNF-handled & AAV-BDNF-stressed \\
\hline Nucleus accumbens core & $419.4 \pm 50.1$ & $479.2 \pm 53.8$ & $537.5 \pm 44.3$ & $473.8 \pm 95.7$ \\
Anterior cingulate cortex & $303.3 \pm 53.9$ & $300.0 \pm 24.0$ & $446.7 \pm 16.2^{\mathrm{a}}$ & $359.5 \pm 47.3$ \\
Prelimbic cortex & $308.3 \pm 50.2$ & $347.9 \pm 20.3$ & $380.0 \pm 38.9$ & $435.7 \pm 64.3$ \\
Infralimbic cortex & $262.5 \pm 29.9$ & $316.7 \pm 22.9$ & $350.0 \pm 29.8$ & $385.7 \pm 61.3$ \\
\hline
\end{tabular}

${ }^{a}$ Significantly different from AAV-GFP-handled, $t$-test, $p \leqslant 0.05$

a

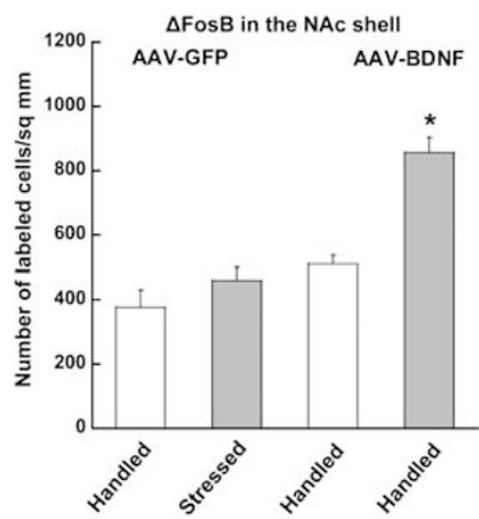

b GFP-Handled

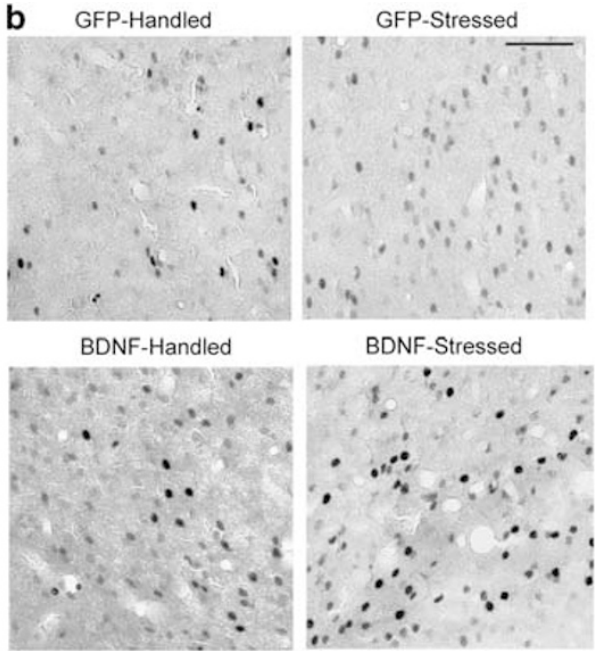

Figure $7 \quad \Delta$ FosB expression in the NAc shell increases only in response to combined VTA BDNF overexpression, single social stress, and repeated AMPH. (a) Number of $\triangle$ FosB-labeled cells in the NAc shell across groups (*p $\leqslant 0.05$ compared with all other groups). (b) Representative photomicrographs of $\Delta$ FosB labeling in the NAc shell of each group; bar $=50 \mu \mathrm{m}$.

Cross-sensitization and sensitization share the common molecular mechanism of enhanced dopamine transmission in mesolimbic circuitry (Imperato et al, 1989; Kalivas and Stewart, 1991), and both behaviors represent increased responsiveness of mesolimbic dopaminergic neurons to drugs of abuse. In addition, intermittent social defeat stress sensitizes NAc dopamine response to cocaine administration (Miczek et al, 2011). Our data show that AAV-mediated VTA $\mathrm{BDNF}$ is enhanced in DA neurons, which may directly increase DA release (Blochl and Sirrenberg, 1996) and metabolism (Altar et al, 1992). As such, the increased number of BDNF-expressing dopamine neurons in the rostral VTA could enhance mesocorticolimbic dopamine neurotransmission, contributing to the prolonged cross-sensitization and the sensitization to AMPH we observed. Our viral infusion resulted in increased VTA BDNF in a physiological range similar to the level of VTA BDNF in rats exposed to intermittent social defeat stress (Fanous et al, 2010), so it is possible that VTA BDNF overexpression induced neuroadaptive changes similar to those induced by intermittent social defeat stress to result in sensitized drug response.

The ability of VTA BDNF to directly modulate sensitization is consistent with the finding that infusions of BDNF into the VTA enhance cocaine sensitization (Horger et al, 1999). Increased endogenous BDNF signaling in the VTA leads to sensitized synaptic response in VTA dopamine neurons after cocaine withdrawal ( $\mathrm{Pu}$ et al, 2006). BDNF in the VTA may act to titrate the effect of social defeat stress on activating mesolimbic neurochemistry by rendering this circuit more vulnerable to stress-induced activation. This enhanced vulnerability might then cause the VTA to be more sensitive to stress or multiple drug challenges, leading to facilitated sensitization. One mechanism for facilitated sensitization may be through AMPH-induced enhancement of calcium signaling, which has been associated with the development of sensitization and produces increased BDNF in regions, such as the cortex and hippocampus (Licata et al, 2000; Shieh et al, 1998; Tao et al, 1998). Calcium signaling specifically in the VTA is important in the development of psychostimulant sensitization (Licata et al, 2000). The presence of increased VTA BDNF may therefore facilitate prolonged synaptic plasticity in the face of a stimulus that produces calcium release (but whose magnitude would not normally result in such prolonged plasticity, such as a single administration of AMPH). In this way, enhanced VTA BDNF may be considered a possible 'risk factor' for development of neuronal and behavioral drug sensitization, which may interact with factors such as stress to further increase 'risk.' This agrees with the role mesolimbic BDNF has been hypothesized to play in addictive behavior (Bolanos and Nestler, 2004).

Intermittent social defeat stress resulted in prolonged BDNF elevation in the VTA (Fanous et al, 2010) and $\triangle$ FosB accumulation in the projection areas of the VTA (Nikulina et al, 2008). In the present study, we found that VTA BDNF overexpression alone was sufficient to induce $\triangle$ FosB accumulation in the NAc and PFC. This finding indicates that persistent elevation of VTA BDNF leads to $\triangle \mathrm{FosB}$ 
accumulation, whose mechanism may be similar to $\Delta \mathrm{FosB}$ elevation observed after repeated social defeat stress.

$\triangle$ FosB accumulation in the NAc could represent a homeostatic mechanism to balance increased VTA BDNF associated with social defeat, as $\triangle F$ FosB in the NAc can enhance the resilience of animals to the aversive effects of chronic social defeat stress (Vialou et al, 2010). The effect of a single episode of social defeat stress alone is too transient to induce considerable $\triangle \mathrm{FosB}$ accumulation in the NAc shell in rats receiving AAV-GFP. However, in the presence of VTA BDNF overexpression, a single defeat stress-induced neuroadaptation may persist, and transcriptional activation of $\triangle \mathrm{FosB}$ may be prolonged in the NAc shell. The mechanism underlying increased $\triangle \mathrm{FosB}$ accumulation in terminal regions resulting from VTA BDNF overexpression requires further investigation.

As discussed above, VTA BDNF overexpression significantly increased $\triangle \mathrm{FosB}$ expression in the PFC and the NAc of handled drug-naive rats. However, repeated AMPH challenges to AAV-BDNF-stressed rats induced a significant increase of $\triangle \mathrm{FosB}$ expression in the NAc shell, but not in the NAc core and PFC, and this effect was region-specific. The explanation for this effect on $\Delta$ FosB expression is likely the differential responsiveness of different regions to stressand drug-related stimuli. This is supported by data demonstrating different anatomical connections and biochemical characteristics of the NAc core and shell (Zahm, 2000), and as such, the subregions may mediate distinct functions related to motor and motivation (Kalivas et al, 1993). Furthermore, recent research indicates regionally specific effects of BDNF signaling in NAc core and shell in drug seeking ( $\mathrm{Li}$ et al, 2013). Also $\Delta \mathrm{FosB}$ modulates synaptic plasticity and reward-related behaviors in a subregion- and cell-type-specific manner in the NAc core and shell (Grueter et al, 2013). Although the involvement of PFC in the sensitization to AMPH is well identified (Cador et al, 1999), no further $\triangle \mathrm{FosB}$ increase was observed in AAV-BDNF-stressed rats after AMPH injections in the PFC. It is possible that $\triangle F$ FosB in PFC is not susceptible to AMPH in rats with BDNF overexpression in the VTA, at least at the time point we observed. Therefore, $\Delta$ FosB expression may vary in different mesocorticolimbic regions in response to the same stimulation (drugs and stress), which may underlie why the current data reflect a distinct trend of increased $\triangle \mathrm{FosB}$ expression only in the NAc shell.

In conclusion, rats with higher VTA BDNF levels developed prolonged AMPH cross-sensitization and sensitization to non-sensitizing dosing regimen of AMPH after social defeat stress. This was associated with increased $\triangle \mathrm{FosB}$ expression in the NAc shell. The present findings suggest that the elevated VTA BDNF could be a risk factor that amplifies vulnerability for drug abuse triggered by socially aversive stimuli.

\section{FUNDING AND DISCLOSURE}

This work was supported by Grant numbers DA024817, DA026451, and MH073930 from the National Institute on Drug Abuse (NIDA) and the National Institute of Mental Health (NIMH). The authors declare no conflict of interest.

\section{ACKNOWLEDGEMENTS}

We gratefully acknowledge Dr Ronald Klein for his assistance with the initial viral vector construction, Dr Stephen Pratt for his assistance for statistics, and Colby Baker for his assistance with the behavioral tests in Experiment 1.

\section{REFERENCES}

Altar CA, Boylan CB, Jackson C, Hershenson S, Miller J, Wiegand SJ et al (1992). Brain-derived neurotrophic factor augments rotational behavior and nigrostriatal dopamine turnover in vivo. Proc Natl Acad Sci USA 89: 11347-11351.

Antelman SM, Eichler AJ, Black CA, Kocan D (1980). Interchangeability of stress and amphetamine in sensitization. Science 207: 329-331.

Baquet ZC, Bickford PC, Jones KR (2005). Brain-derived neurotrophic factor is required for the establishment of the proper number of dopaminergic neurons in the substantia nigra pars compacta. J Neurosci 25: 6251-6259.

Bekinschtein P, Cammarota M, Katche C, Slipczuk L, Rossato JI, Goldin A et al (2008). BDNF is essential to promote persistence of long-term memory storage. Proc Natl Acad Sci USA 105: 2711-2716.

Berton O, McClung CA, Dileone RJ, Krishnan V, Renthal W, Russo SJ et al (2006). Essential role of BDNF in the mesolimbic dopamine pathway in social defeat stress. Science 311: 864-868.

Blochl A, Sirrenberg C (1996). Neurotrophins stimulate the release of dopamine from rat mesencephalic neurons via Trk and p75Lntr receptors. J Biol Chem 271: 21100-21107.

Bolanos CA, Nestler EJ (2004). Neurotrophic mechanisms in drug addiction. Neuromol Med 5: 69-83.

Cador M, Bjijou Y, Cailhol S, Stinus L (1999). D-amphetamineinduced behavioral sensitization: implication of a glutamatergic medial prefrontal cortex-ventral tegmental area innervation. Neuroscience 94: 705-721.

Cheng C-Y, Hong C-J, Yu YWY, Chen T-J, Wu H-C, Tsai S-J (2005). Brain-derived neurotrophic factor (Val66Met) genetic polymorphism is associated with substance abuse in males. Mol Brain Res 140: 86-90.

Cohen-Cory S, Kidane AH, Shirkey NJ, Marshak S (2010). Brainderived neurotrophic factor and the development of structural neuronal connectivity. Dev Neurobiol 70: 271-288.

Covington HE 3rd, Miczek KA (2001). Repeated socialdefeat stress, cocaine or morphine. Effects on behavioral sensitization and intravenous cocaine self-administration 'binges'. Psychopharmacology (Berl) 158: 388-398.

de Jong JG, van der Vegt BJ, Buwalda B, Koolhaas JM (2005a). Social environment determines the long-term effects of social defeat. Physiol Behav 84: 87-95.

de Jong JG, Wasilewski M, van der Vegt BJ, Buwalda B, Koolhaas JM (2005b). A single social defeat induces short-lasting behavioral sensitization to amphetamine. Physiol Behav 83: 805-811.

Deroche V, Piazza PV, Le Moal M, Simon H (1994). Social isolationinduced enhancement of the psychomotor effects of morphine depends on corticosterone secretion. Brain Res 640: 136-139.

Di Chiara G, Imperato A (1988). Drugs abused by humans preferentially increase synaptic dopamine concentrations in the mesolimbic system of freely moving rats. Proc Natl Acad Sci USA 85: 5274-5278.

Egan MF, Kojima M, Callicott JH, Goldberg TE, Kolachana BS, Bertolino A et al (2003). The BDNF val66met polymorphism affects activity-dependent secretion of BDNF and human memory and hippocampal function. Cell 112: 257-269.

Fanous S, Hammer RP Jr, Nikulina EM (2010). Short- and longterm effects of intermittent social defeat stress on brain-derived neurotrophic factor expression in mesocorticolimbic brain regions. Neuroscience 167: 598-607. 
Fanous S, Terwilliger EF, Hammer RP Jr, Nikulina EM (2011). Viral depletion of VTA BDNF in rats modulates social behavior, consequences of intermittent social defeat stress, and long-term weight regulation. Neurosci Lett 502: 192-196.

Flanagin BA, Cook EH Jr, de Wit H (2006). An association study of the brain-derived neurotrophic factor Val66Met polymorphism and amphetamine response. Am J Med Genet Part B Neuropsychiatr Genet 141B: 576-583.

Gao GP, Alvira MR, Wang L, Calcedo R, Johnston J, Wilson JM (2002). Novel adeno-associated viruses from rhesus monkeys as vectors for human gene therapy. Proc Natl Acad Sci USA 99: 11854-11859.

Geyer MA, Russo PV, Segal DS, Kuczenski R (1987). Effects of apomorphine and amphetamine on patterns of locomotor and investigatory behavior in rats. Pharmacol Biochem Behav 28: 393-399.

Grueter BA, Robison AJ, Neve RL, Nestler EJ, Malenka RC (2013). $\triangle$ FosB differentially modulates nucleus accumbens direct and indirect pathway function. Proc Natl Acad Sci USA 110: 1923-1928.

Horger BA, Iyasere CA, Berhow MT, Messer CJ, Nestler EJ, Taylor JR (1999). Enhancement of locomotor activity and conditioned reward to cocaine by brain-derived neurotrophic factor. J Neurosci 19: 4110-4122.

Imperato A, Puglisi-Allegra S, Casolini P, Zocchi A, Angelucci L (1989). Stress-induced enhancement of dopamine and acetylcholine release in limbic structures: role of corticosterone. Eur J Pharmacology 165: 337-338.

Kalivas PW, Churchill L, Klitenick MA (1993). The circuitry mediating the translation of motivational stimuli into adaptive motor responses. In: Kalivas PWBarnes CD (eds). Limbic Motor Circuits and Neuropsychiatry. CRC Press: Boca Raton, FL, USA, pp 237-288.

Kalivas PW, Stewart J (1991). Dopamine transmission in the initiation and expression of drug- and stress-induced sensitization of motor activity. Brain Res Rev 16: 223-244.

Kelz MB, Chen J, Carlezon WA Jr, Whisler K, Gilden L, Beckmann AM et al (1999). Expression of the transcription factor deltaFosB in the brain controls sensitivity to cocaine. Nature 401: 272-276.

Klein RL, Meyer EM, Peel AL, Zolotukhin S, Meyers C, Muzyczka N et al (1998). Neuron-specific transduction in the rat septohippocampal or nigrostriatal pathway by recombinant adenoassociated virus vectors. Exp Neurol 150: 183-194.

Li X, Dejoseph MR, Urban JH, Bahi A, Dreyer JL, Meredith GE et al (2013). Different roles of BDNF in nucleus accumbens core versus shell during the incubation of cue-induced cocaine craving and its long-term maintenance. J Neurosci 33: 1130-1142.

Licata SC, Freeman AY, Pierce-Bancroft AF, Pierce RC (2000). Repeated stimulation of L-type calcium channels in the rat ventral tegmental area mimics the initiation of behavioral sensitization to cocaine. Psychopharmacology (Berl) 152: 110-118.

McClung CA, Ulery PG, Perrotti LI, Zachariou V, Berton O, Nestler EJ (2004). DeltaFosB: a molecular switch for long-term adaptation in the brain. Brain Res Mol Brain Res 132: 146-154.

Miczek KA, Covington HE 3rd, Nikulina EM Jr, Hammer RP (2004). Aggression and defeat: persistent effects on cocaine self-administration and gene expression in peptidergic and aminergic mesocorticolimbic circuits. Neurosci Biobehav Rev 27: 787-802.

Miczek KA, Nikulina E, Kream RM, Carter G, Espejo EF (1999). Behavioral sensitization to cocaine after a brief social defeat stress: c-fos expression in the PAG. Psychopharmacology (Berl) 141: 225-234.

Miczek KA, Nikulina EM, Shimamoto A, Covington HE 3rd (2011). Escalated or suppressed cocaine reward, tegmental BDNF, and accumbal dopamine caused by episodic versus continuous social stress in rats. J Neurosci 31: 9848-9857.

Nestler EJ, Kelz MB, Chen J (1999). DeltaFosB: a molecular mediator of long-term neural and behavioral plasticity. Brain Res 835: 10-17.
Nikulina EM, Arrillaga-Romany I, Miczek KA, Hammer RP Jr (2008). Long-lasting alteration in mesocorticolimbic structures after repeated social defeat stress in rats: time course of muopioid receptor mRNA and FosB/DeltaFosB immunoreactivity. Eur J Neurosci 27: 2272-2284.

Nikulina EM, Covington HE 3rd, Ganschow L, Hammer RP Jr, Miczek KA (2004). Long-term behavioral and neuronal crosssensitization to amphetamine induced by repeated brief social defeat stress: Fos in the ventral tegmental area and amygdala. Neuroscience 123: 857-865.

Paxinos G, Watson C (2007). The Rat Brain in Stereotaxic Coordinates. Elsevier: Amsterdam, The Netherlands.

Perrotti LI, Hadeishi Y, Ulery PG, Barrot M, Monteggia L, Duman RS et al (2004). Induction of DeltaFosB in rewardrelated brain structures after chronic stress. J Neurosci 24: 10594-10602.

Piazza PV, Deminiere JM, le Moal M, Simon H (1990). Stress- and pharmacologically-induced behavioral sensitization increases vulnerability to acquisition of amphetamine self-administration. Brain Res 514: 22-26.

Pierce RC, Bari AA (2001). The role of neurotrophic factors in psychostimulant-induced behavioral and neuronal plasticity. Rev Neurosci 12: 95-110.

Pu L, Liu Q-s, Poo M-m (2006). BDNF-dependent synaptic sensitization in midbrain dopamine neurons after cocaine withdrawal. Nat Neurosci 9: 605-607.

Robinson TE, Angus AL, Becker JB (1985). Sensitization to stress: the enduring effects of prior stress on amphetamine-induced rotational behavior. Life Sci 37: 1039-1042.

Segal DS, Mandell AJ (1974). Long-term administration of d-amphetamine: progressive augmentation of motor activity and stereotypy. Pharmacol Biochem Behav 2: 249-255.

Shieh PB, Hu SC, Bobb K, Timmusk T, Ghosh A (1998). Identification of a signaling pathway involved in calcium regulation of BDNF expression. Neuron 20: 727-740.

Sinha R (2008). Chronic stress, drug use, and vulnerability to addiction. Ann NY Acad Sci 1141: 105-130.

Stewart J, Badiani A (1993). Tolerance and sensitization to the behavioral effects of drugs. Behav Pharmacol 4: 289-312.

Swanson LW (1982). The projections of the ventral tegmental area and adjacent regions: a combined fluorescent retrograde tracer and immunofluorescence study in the rat. Brain Res Bull 9: 321-353.

Tao X, Finkbeiner S, Arnold DB, Shaywitz AJ, Greenberg ME (1998). Ca2 + influx regulates BDNF transcription by a CREB family transcription factor-dependent mechanism. Neuron 20: 709-726.

Tidey JW, Miczek KA (1996). Social defeat stress selectively alters mesocorticolimbic dopamine release: an in vivo microdialysis study. Brain Res 721: 140-149.

Tsai SJ (2007). Increased central brain-derived neurotrophic factor activity could be a risk factor for substance abuse: implications for treatment. Med Hypotheses 68: 410-414.

Uhl GR, Liu QR, Walther D, Hess J, Naiman D (2001). Polysubstance abuse-vulnerability genes: genome scans for association, using 1,004 subjects and 1,494 single-nucleotide polymorphisms. Am J Hum Genet 69: 1290-1300.

Vialou V, Robison AJ, LaPlant QC, Covington HE, Dietz DM, Ohnishi YN et al (2010). DeltaFosB in brain reward circuits mediates resilience to stress and antidepressant responses. Nat Neurosci 13: 745-752.

Xiao X, Li J, Samulski RJ (1998). Production of high-titer recombinant adeno-associated virus vectors in the absence of helper adenovirus. J Virol 72: 2224-2232.

Zahm DS (2000). An integrative neuroanatomical perspective on some subcortical substrates of adaptive responding with emphasis on the nucleus accumbens. Neurosci Biobehav Rev 24: $85-105$. 